\title{
Characterization, expression profiles, intracellular distribution and association analysis of porcine PNAS-4 gene with production traits Delin $\mathrm{Mo}^{1,2}$, Zhengmao $\mathrm{Zhu}^{3}$, Marinus FW te $\mathrm{Pas}^{4}$, Xinyun $\mathrm{Li}^{1}$, Shulin Yang1, Heng Wang1, Huanling Wang ${ }^{1}$ and Kui $\mathrm{Li}^{* 1}$
}

Address: ${ }^{1}$ State Key Laboratory of Animal Nutrition, Institute of Animal Science, Chinese Academy of Agricultural Science, Beijing 100094, PR China, ${ }^{2}$ School of Life Science, Sun Yat-Sen University, Guangzhou 510006, PR China, ${ }^{3}$ Department of Genetics and Cell biology, College of life sciences, Nankai University, Tianjin 300071, PR China and ${ }^{4}$ Animal Breeding and Genomics Centre, Wageningen University and Research Centre, Lelystad, The Netherlands P.O. Box 65, 8200 AB Lelystad, The Netherlands

Email: Delin Mo - modelin@mail.sysu.edu.cn; Zhengmao Zhu - zhuzhengmao@gmail.com; Marinus FW te Pas - marinus.tepas@wur.nl; Xinyun Li - lxylhz@yahoo.com.cn; Shulin Yang - hi_ysl@yahoo.com.cn; Heng Wang - muwhy@hotmail.com;

Huanling Wang - hbauwhl@hotmail.com; Kui Li* - likuihau@yahoo.com

* Corresponding author

Published: 30 June 2008

BMC Genetics 2008, 9:40 doi:10.1 186/147|-2156-9-40
Received: 23 December 2007

Accepted: 30 June 2008

This article is available from: http://www.biomedcentral.com/I47I-2I56/9/40

(c) 2008 Mo et al; licensee BioMed Central Ltd.

This is an Open Access article distributed under the terms of the Creative Commons Attribution License (http://creativecommons.org/licenses/by/2.0), which permits unrestricted use, distribution, and reproduction in any medium, provided the original work is properly cited.

\begin{abstract}
Background: In a previous screen to identify differentially expressed genes associated with embryonic development, the porcine PNAS-4 gene had been found. Considering differentially expressed genes in early stages of muscle development are potential candidate genes to improve meat quality and production efficiency, we determined how porcine PNAS-4 gene regulates meat production. Therefore, this gene has been sequenced, expression analyzed and associated with meat production traits.

Results: We cloned the full-length cDNA of porcine PNAS-4 gene encoding a protein of 194 amino acids which was expressed in the Golgi complex. This gene was mapped to chromosome 10, q1 I16, in a region of conserved synteny with human chromosome I where the human homologous gene was localized. Real-time PCR revealed that PNAS-4 mRNA was widely expressed with highest expression levels in skeletal muscle followed by lymph, liver and other tissues, and showed a downregulated expression pattern during prenatal development while a up-regulated expression pattern after weaning. Association analysis revealed that allele C of SNP A 8 I3C was prevalent in Chinese indigenous breeds whereas $A$ was dominant allele in Landrace and Large White, and the pigs with homozygous $C C$ had a higher fat content than those of the pigs with other genotypes $(P<0.05)$.

Conclusion: Porcine PNAS-4 protein tagged with green fluorescent protein accumulated in the Golgi complex, and its mRNA showed a widespread expression across many tissues and organs in pigs. It may be an important factor affecting the meat production efficiency, because its downregulated expression pattern during early embryogenesis suggests involvement in increase of muscle fiber number. In addition, the SNP AI8I3C associated with fat traits might be a genetic marker for molecular-assisted selection in animal breeding.
\end{abstract}




\section{Background}

Differentially expressed genes in the early stages of muscle development may be potential candidate genes to improve meat quality and quantity $[1,2]$. Recent studies showed that differential expression of genes during muscle development in prenatal pigs is associated with the differential stages of myogenesis [3,4], and expression patterns of these genes differ between pig breeds with different muscle characteristics $[5,6]$.

An EST [GenBank: $\underline{\text { AA063650] }}$ was identified showing differential expression during the early stages of muscle development [7]. In order to identify this EST with expression associated with prenatal muscle development, a fulllength cDNA library was constructed using 55-day Chinese Tongcheng pig fetus skeletal muscle [7]. From the cDNA library, a 2285-bp cDNA clone was obtained which was identical with this EST. After BLAST search in the nonredundant (nr) sequence database, it was found to be homologous to a clone DKFZp586C1019 [GenBank: AL049397] which is part of Homo sapiens PNAS-4 gene (also called C1orf121) encoding the CGI-146 protein. Recently, a report showed that human PNAS-4 is a novel pro-apoptotic protein activated during the early response to DNA damage [8]. Furthermore, this gene was also predicted as one of the targets of p53 tumor suppressor via mathematical modeling and quantitative data analysis [9]. Presently, Xenopus laevis PNAS-4 protein has been purified and confirmed by Western blot [10]. However, the biological functions of PNAS-4, especially the role in muscle development, are still unclear.

The aim of the present study was to characterize the porcine PNAS-4 gene by obtaining its sequence, and gain insight into its potential physiological role in muscle development related to meat production by studying subcellular localization, the temporal prenatal expression pattern, postnatal tissue expression levels and trait association analysis.

\section{Results}

\section{Molecular cloning and sequence analysis}

The full-length cDNA of porcine PNAS-4 gene consists of 4,059 bp that contains an open reading frame (ORF) of 582-bp encoding a protein of 194 amino acids with a calculated molecular mass of $21.4 \mathrm{kDa}$ and an isolectric point (pI) of 4.807 (Figure 1). Two polyadenylation signals (AATAAA) were observed at positions 821 to 826 and 2307 to 2312 upstream of the poly (A) stretch. The BrdBox (AGCTTTA) and GY-Box (GTCTTCC) were found in the 3' untranslated region (UTR) (Figure 1). The mRNA sequence of this gene has been submitted to GenBank [GenBank: DQ435075].
Comparison of the porcine amino acid sequence with the proteins of seven species reported in GenBank shows that the porcine putative protein possesses a high level of identity (94-98\%) with mammals and fowls, and it shares $74 \%$ identity with Xenopus laevis throughout the protein sequence. The porcine protein contained several conserved motifs such as C-terminal microbody targeting signal (CMTS), N-myristoylation and a Protein kinase $\mathrm{C}$ phosphorylation site (Figure 2). In addition, it showed that the porcine PNAS-4 encoded a non-secretory protein without signal peptide and transmembrane regions.

\section{Spatial and temporal expression pattern}

The relative expression of the porcine PNAS-4 transcript in various pig tissues showed highest expression in skeletal muscle (in decreasing order: gastrocnemius, semitendinosus, longissimus dorsi and biceps femoris) and lymph node. Lower expression levels were determined in the liver, large intestine, backfat, heart, small intestine, stomach, spleen, lung, kidney and brain (Figure 3).

Figure 4 showed that the expression level of porcine PNAS-4 seemed to decrease gradually during embryonic development of Landrace and Tongcheng pig breeds, which was significant in Landrace pigs between 33 days post conception (dpc) and $90 \mathrm{dpc}$. This was consistent with the results of semi-quantitative RT-PCR [7]. Curiously, after birth, the amount of porcine PNAS-4 mRNA in skeletal muscles increased drastically $(P<0.01)$. However, the mRNA expression on the day of weaning (28-day neonate) was lower than the second day after birth and adult $(P<0.05)$. After maturity, the mRNA expression of porcine PNAS-4 reached a peak level $(P<0.01)$.

\section{Intracellular distribution}

The CGI-146-GFP fusion proteins localized in the Golgi complex (Figure 5), which was identified by the complementation tests using the homo-functional P4-pEGFP-N3 construct. Green fluorescence was detected in the cytoplasm of the control cells transfected with pEGFP vector alone (E-H, Figure 5).

\section{Chromosome assignment}

The somatic cell hybrid (SCH) panel revealed that the porcine PNAS-4 gene was assigned to SSC10 (q11-q16) (probability of regional localization: 0.9998, error risk < $0.1 \%$ ). Two-point analysis of INRA-University of Minnesota porcine radiation hybrid (IMpRH) panel revealed that the porcine PNAS-4 was closely linked to SW497 (LOD $=13.68,28 \mathrm{cRs}$ ) with $22 \%$ retention frequencies. This result was consistent with the SCH panel. The corresponding conserved syntenic region on human chromosome was the end of Homo sapiens chromosome 1 long $\operatorname{arm}($ HSC1q)[11]. 


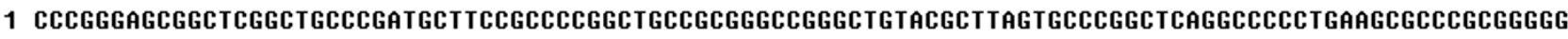
101 TGAGAGCGGCCTCCGGCCCCGCGGAGACGGAGCGGCTTGAGGACGAGGCGGCGGCCGCGGGGAGGAGGATGGGGGCTAACCAATTAGTGGTGCTCAACGT

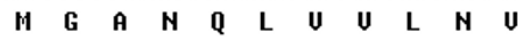

201 GTACGACATGTACTGGATGAACGAGTACACCTCATCCATCGGAATTGGAGTTTTTCATTCAGGAATTGAGGTATATGGCAGAGAGTTTGCTTATGGTGGC

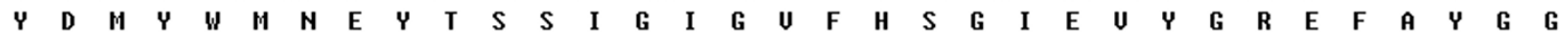

391 CATCCTTACСССTTTCTGGAATATTTGAAATTTCCCCAGGAAATGCTTCTGAACTAGGAGAAACATTTAAATTTAAAGAAGCTGTTGTTTTGGGGAGCA

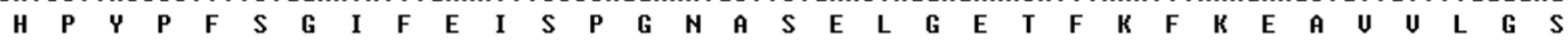
401 CTGACTTCCTAGAAGATGATATAGAAAAAATTGTAGAAGAATTGGGAAAAGAATACAAAGGCAATGCCTATCATTTGATGCATAAAAACTGCAATCATTT $\begin{array}{llllllllllllllllllllllllllllllllllllll}\text { T } & D & F & L & E & D & D & I & E & K & I & U & E & E & L & G & K & E & Y & K & G & N & A & Y & H & L & M & H & K & N & C & N & H & F\end{array}$

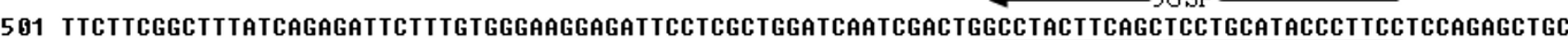

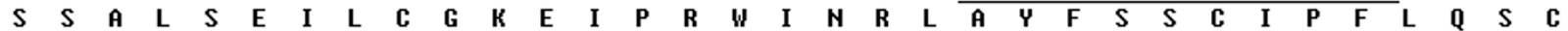
601 CTCCCGAAGGAGTGGCTGACTCCCGCGGCCCTGCAGTCCAGCGTCAGCCAGGAGCTCCAGGACGAACTGGAGGAGGCAGAGGATGCGGCGGCCTCCGCCT

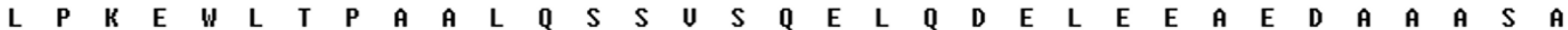

701 CCATGGGCAGCGCTTCAGCAGGCTCCAGGCCTGGGCGCCACACCAAACTCTAGGGGTCTCCAAAGTCACACGCTCAGAACTGGCCCTGGCAGTTGACTAT

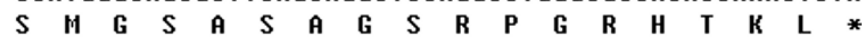

801 CССТAGAGAAAAAGTCAAAGAATAAATGCCCTTTGGATATTTTGTATGCAAAGATGGCTCTCCСCCAAATCCCAGGTTITCAGCTCAGGATTATATTTGT

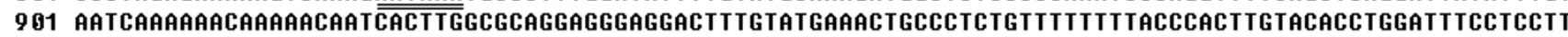
1091 CTGTTTTGTACAAGCTCTGTTAAGTTATGTTTACAGTATTTCGTATCGCTGTTTACAAATCTCGCATGGACTTCCTGCCACCATGAAAGAAGAAAGCCTT 11 CCСGTCTTCAGCAGCGAGGCCAGGCCTCTCTGTGCACTTCCGACAGCGGCCCCAGCTGCGGCCTGAGCAGTAGGCCCGCGAGGAGGTGCTCACGCACTTA 1201 GAGTCACCACCACCTGCCTCACGGTTGTCTITTAGGCGCGCTGGTCTTCC TAACACGTIGGCACCAGGGTGCACAGAGGTGAAGGAGCACACGCAGCCC 1301 TGAGTCCGTGGTCCGAGTGAGGTGGCCCCACCCCAGGCTGCCTTCCTCCTCGCCCACCCCCCCACCCCGGGCAGCACATCTCCGGAGGTCCCCACCCAG 1491 CGGTTACTTTCTTCCCAAATGTGTGTCCACCСTCTCGAGGTGGCACACCCTGGTGTCTGCCAGGCTTTAGCGCCTCTGATGCTGTAGGTAGATGTTTTTG 1501 GTTACAGATCCTCTTGATAGTAACGGATGATGTTTTTGCACATGGGTTGGGGGGCTTCCTTTTATCTTAATACGTACTGATCTCCCTGCACAGGAGCT $\longleftarrow$ GAPR

1601 TCTTCGTGGGGTAGGACTATCCTAAGCGGTAGCCTTCTGAGTAGCAGTATGAGTTGACATTCAACTGCTITTAACTATTCAAGCTACCTITTCTACTACA 1701 CСTTGAAAACTAGAGTCTTCAAGTAACACTCTCCAGAAAGTCAATACTITGATAATGTAAACGTTITATGCACCATAGCAGAAAGAGTATGTTGGAATTG 1891 GTTAGTTTCTTACGGTAGTTTCACCTCCCAATAGAAAGCCTCGCCTCACTGACCTCTTGTTGGAAAATCACACGTACGCGTCTTACAGGTCATCTITTCC 1901 GTTCTCTCAGATGTATGTCTCTTACTTAACTGACTCTAAGAATGAAGCTGTCACCACAGATGAGTCCTCACTAGCAGGGAGCCTGTCTGCTCAAGTCTAC 2091 TCCCAGTTTGACCCTTGGATGTCAGAGCCCCGTCATTACATGTCACATTCAGTGTTTCTGCCTTAAGAGCGAATGTCCTACACAGAGTTTTGGATGCAGT 2101 GTATAAATTATCCAAGGCAGTGACTTCAGCGTTAGAGATATTGT TAGCTTTAAAGTCGTCTACGTTTCTTTAAACGTCTTCATTGGGTTGTTTGCTGCTG 2201 TTCTTTGTAAGGACCCATATCCTTCAGTAAACTACATTITTTAACTTTTCCATAAGCTGATTTTGATTGATTTTTATCAAATTAAGCACAACCTGTTCAT 2301 AGGGGAAATAAACTTTGGGTTTGACCTGAGGAAAATGAACCCACTTAACCTAATTTATGCTITTGGCGGTTITGTTTCTGGAGAGGAAAGCCTTGGTGGA

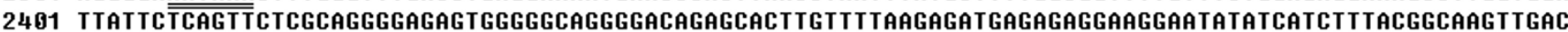
2501 ITGGTTCAGGTCTAAAAATGAGATITAGAACAAAATGCTAAAAAGACTCTTGACTGACTTGGTTCACTCCAAGAAGAGTCTTAGCACCAAAACCCAGGTT 2601 AGTGAAAAAAACGTTTGATGAAGTITGCTTGGGTTCITTITAAAATAATGTGGATTCCAGTITTTTCTAATCCATTCACATGTACATGATTITAAATCTG 2701 TGCTCCTGACGCGCATGGCAGAGCGGTCGTCACT TAGGCGCGTGGCGGGGGGGCCCCAGGACCCTCCCGCAGTTCTCCGAGCCCAGCATACAAATGACTT 2801 TCGTGTTACTGTGTTGTATTGACGTTCATCCGCAGCATTTAGAGTTTAGAAATGACGTTAAGGACCCTGGTAAAAAGAAATAGTGGCCTAAGGCCATGGA 2991 TCATACAGTAAGATAACCATTGTTGGACATGAGATTGCTCGCAATCTTAATCCCGCTCGAGGTCGAGAGCTTAAAGTGTCTTTTGCTTTAGAAATTCCCG 3 פ01 TITAAGTTAGTTTGCTCATTGCAGTTCAAAGCTGAGAAGGAATTAACTAACATTTAGCCACCTITCCCTCGCCCTTAGAGGAGGAGAATCTCGCTCTCAG 3191 CСTGAGCTCTGTTAAGAAAAATCCTCTATCACAGATGCTGTCATTAAGATACCTGTGACATGATGGCGTCAGATGCTCTCTTTGTGGTTGTAACCAAGTG 32 B1 AAACGCGTITCTCATGTGGCTGAGACAGTCGGAGAGCTITGAGGGAGTCAGAAGCTCCTGGITTCTCCTCITTGITITTGGGCCGTTGGGTITGCTITI 3301 GGTTTTGTTTTCAACCCTAAGAAGGGGGCACCGGCTTTGGAAAGCGGAGCCTGCGGAGTTGCAGGAGGCAGCGATGCGGTACAGGAAGCCTCCACTCGAT 3401 CCCTGAAATCCAGCCAACGGTTGCTCTGACCCACAGCAATAGCGCAGGTTCTCACCACCAGCATITGTACAGAGCAGGGAATCCTGGTTITAAGCCGATG 3501 GCTAGCATGGTGCGTGGGAGGAGATTCTGCTCTATGGCAGCTGCAGGACCCCACATCTACAGCCTCTTTCCACTGCAAGACGGTAGAAACACATTCACTG 3691 CITCAGGGTTCGAATCTGTGTGTCTTCTTGCGGCTCCATITCTATCCAGTATGCTGTAATITTGATACATGCTGTATITTCITTCCGTGACTCAGTITAA 37 A AAGGCTTGGGTTITTTGTTCAGCAAGCTGGCCATCCTGCCGCTGAATCTCCTTCCCTTCTGTGAGGTTITAGAGCGCAGCCCAGTCATTAGACTCCCTCT 3801 GTCTACTCAGTCCACACACATCTTCATCGTITGCAAGGTCTTACGGCTGTTAAAGAATCTITATGAACCCGAAGATGATTTCTCGTGAAGTTGAATGCAA 3901 ATGTACTGTCATTCATAGTGTTTATATTAAAAAAAAAAAAAAATACCAGGAATCTTCACTTTTGCTACCTTGATATAGCATTGGGCTATCATGTTAACAT 4901 TGAAATACATCAATTTATTAAAAAATACTTTTCTAAGAAAAAAAAAAAAAAAAAAAAAB

Figure I

Nucleotide and deduced amino acid sequence of porcine PNAS-4. The polyadenylation signals (AATAAA) are doubleunderlined; and the two elements named Brd-Box and GY-Box are boxed, separately. Primer site for 5' RACE assays is single underlined.

\section{Polymorphism detection and association with economic traits}

Comparative sequencing revealed 9 and 5 polymorphisms within two PCR amplified fragments [GenBank: $\underline{\mathrm{DQ} 406743}$ and DQ435075] which were parts of PNAS-4 genomic DNA. Because of linkage disequilibrium among several polymorphisms, two single nucleotide polymor- phisms (SNPs) were selected for further study. The T1400C SNP within intron 2 was detectable after digestion with Sty I, resulting in a 762-bp PCR amplicon produced allele T (762 bp) and allele C (549 bp and $213 \mathrm{bp}$ ). The other SNP, A1813C within the 3'UTR, located more than $20 \mathrm{~kb}$ away from the T1400C SNP in genome, was harbored in a 789-bp PCR amplicon and digested by Msp 
Majority $M G A N Q L V V L N V Y D M Y U M N E Y T S S I G I G V F H S G I E V Y G R E F A Y G G H P Y P F S G I F E I S P G N A S E L G E$

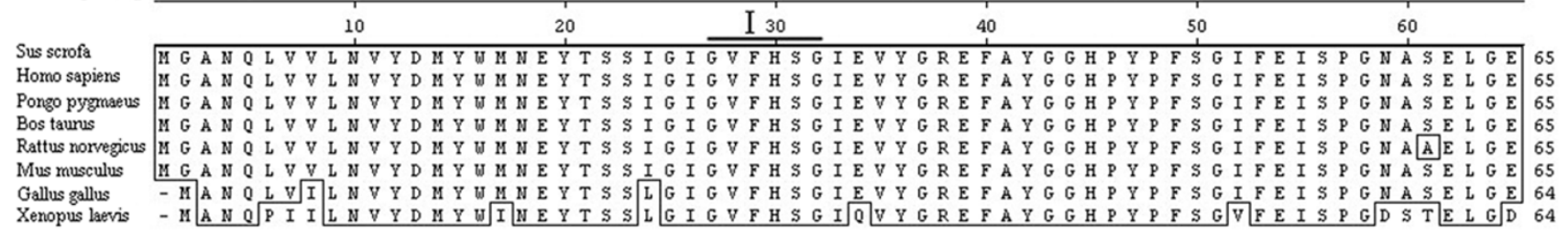

Majority TFKFKEAVVLGSTDFLEDDIEKIVEELGKEYKGNAYHLMHKNCNHFSSALSEILCGKEIPRWINR

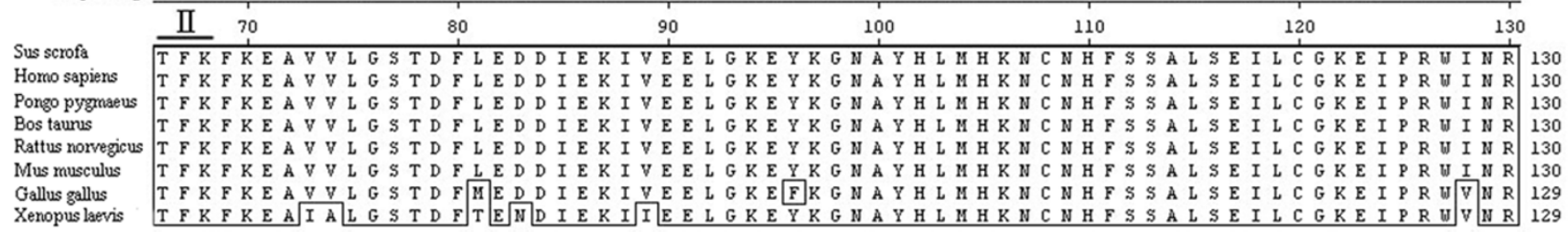
Majority LAYFSSCIPFLOSCLPKEWLTPAALQSSVSQELODELEEAEDAAASASMASTAAGSRPGRHTKL

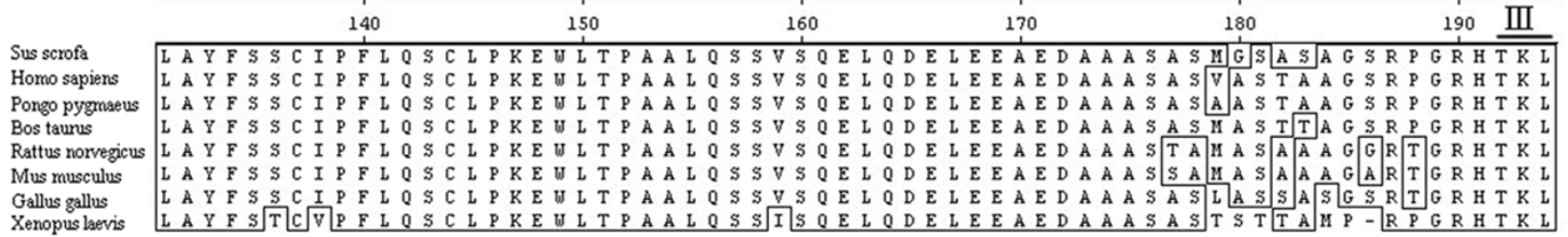

Figure 2

Multiple amino acid sequence alignment of porcine CGI-146. Different amino acid residues among species are presented with boxes. The three highly conserved motifs ( $\mathrm{N}$-myristoylation, Protein kinase $\mathrm{C}$ phosphorylation and MCTS) are indicated by roman letters (I - III), respectively.

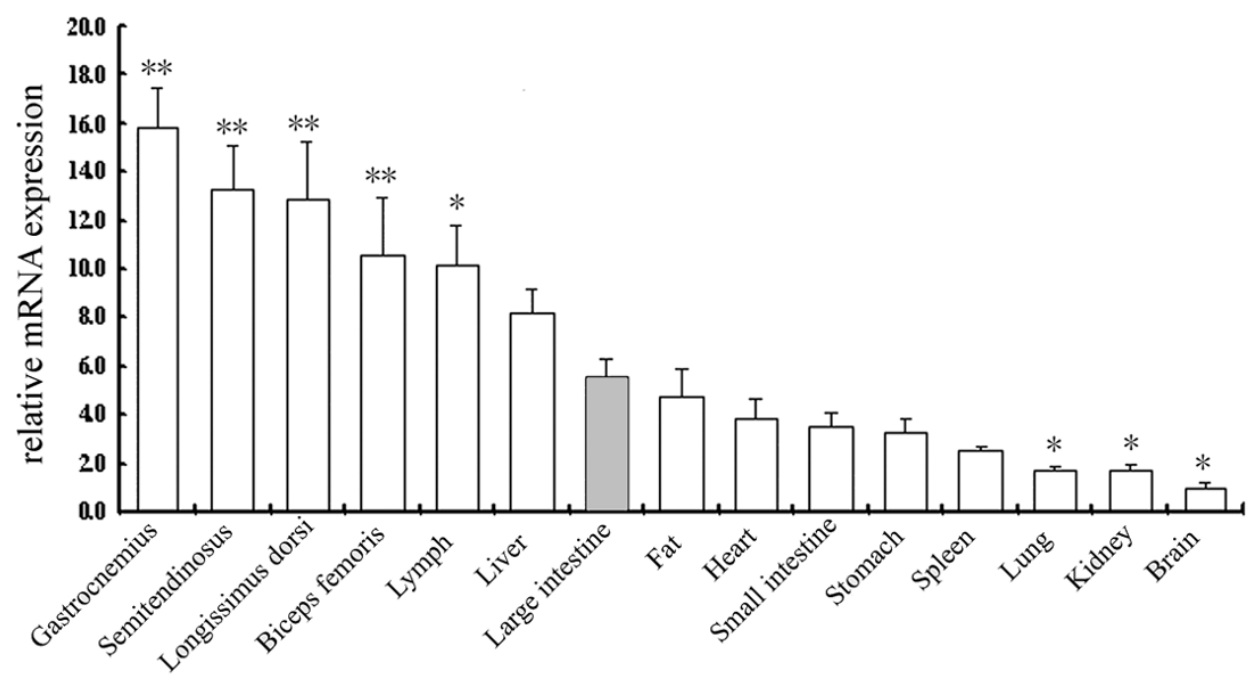

Figure 3

The tissue distribution of porcine PNAS-4 mRNA assessed by qPCR. The values shown in this figure are the averages of three independent experiments. Error bars represent the SD $(n=3)$ of relative mRNA expression levels of PNAS-4 normalized to ACTB. The values were normalized to endogenous ACTB expression and the value of PNAS-4 in brain was arbitrarily set to I.0. In order to tell the detailed difference between the varied tissues, large intestine was used as a control. $\left(^{*}\right.$ represents $P$ $<0.05$, ** represents $P<0.0$ I). 


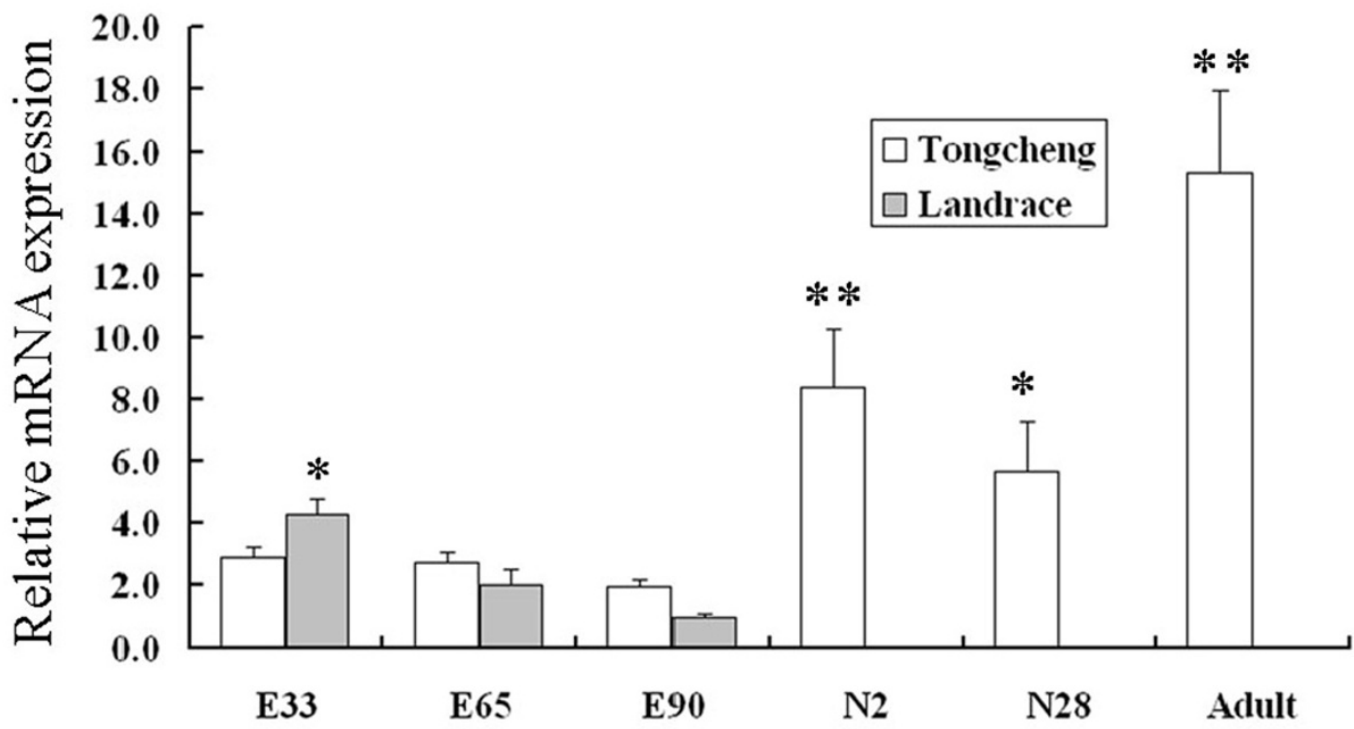

\section{Figure 4}

The developmental profile of porcine PNAS-4 mRNA expression. Porcine PNAS-4 mRNA expression levels in skeletal muscle normalized against ACTB during embryonic development and the postnatal period, measured by qPCR. Error bars represent SD $(n=3)$. Results were averaged from three independent assays during all stages observed. Symbols used are: $* P<$ 0.05; **P < 0.0I. E33: embryonic day 33; E65: embryonic day 65; E90: embryonic day 90; N2: muscle from 2-day neonate; N28: muscle from 28-day neonate.

I, resulting in allele A (789 bp) and allele C (606 bp and $183 \mathrm{bp})$.

Analysis of polymorphism revealed that allele C for both polymorphisms (T1400C and A1813C) was prevalent in four Chinese indigenous pig breeds whereas the allele $\mathrm{T}$ (T1400C) and the allele A (A1813C) respectively had higher frequencies in Landrace and Large White (Table 1). The two SNPs could be linked in Landrace, Large White pigs and a pair of three breed-crosses (data not shown). Therefore, we selected one of the two SNPs for association analysis. Three significant associations were observed

Table I: Genotypes of porcine SNPs TI400C and AI8I3C in different pig breeds

\begin{tabular}{|c|c|c|c|c|c|c|c|}
\hline \multirow[t]{2}{*}{ Pig Breeds } & \multirow[t]{2}{*}{ No. } & \multicolumn{3}{|c|}{ TI400C (Sty I) } & \multicolumn{3}{|c|}{$\mathrm{A}|8| 3 \mathrm{C}(\mathrm{Msp} \mathrm{I})$} \\
\hline & & $T T$ & $T C$ & CC & $A A$ & $A C$ & $C C$ \\
\hline Wuzhishan & 43 & 0 & 0 & 43 & 7 & 18 & 18 \\
\hline Xiang & 42 & 0 & 21 & 21 & 8 & 13 & 21 \\
\hline Bamaxiang & 45 & 0 & 14 & 31 & 0 & 0 & 45 \\
\hline Tongcheng & 44 & I & 11 & 32 & 5 & 11 & 28 \\
\hline Landrace & 15 & 12 & 0 & 3 & 12 & 0 & 3 \\
\hline Large White a & 19 & 15 & 0 & 4 & 15 & 0 & 4 \\
\hline Large White b & 196 & 139 & 54 & 3 & 139 & 54 & 3 \\
\hline
\end{tabular}

a DNA samples collected from our experimental pig group. b DNA samples collected from two experimental Large White selection lines originating from one commercial population. between the A1813C SNP genotypes and three fat-related traits (Table 2). For the three considered traits, homozygous CC pigs of our experimental population showed higher values than those of the pigs with other genotypes $(P<0.05)$.

\section{Discussion}

Differential expression of genes during a biological process suggests a direct or indirect relationship between the genes and the biological process[12]. An EST [GenBank: AA063650] was identified showing differential expression during the early stages of muscle development [7]. Therefore, the full-length cDNA of the PNAS-4 gene was obtained and analyzed for study its structure and biological functionality. This manuscript reports the cDNA and amino acid sequences of the gene, its mRNA expression profiles, protein localization, and functional analysis in muscle tissue formation and meat production.

\section{PNAS-4 cDNA and amino acid analysis}

Full-length cDNA sequence analysis revealed high identity of the gene at both the mRNA and the amino acid level with mammalian and avian species. This may indicate both structural and functional conservation of the gene. The Brd-Box and GY-Box within the 3'UTR suggests that the PNAS-4 expression was regulated negatively at the post-transcriptional level, both temporal and spatial [1315]. 

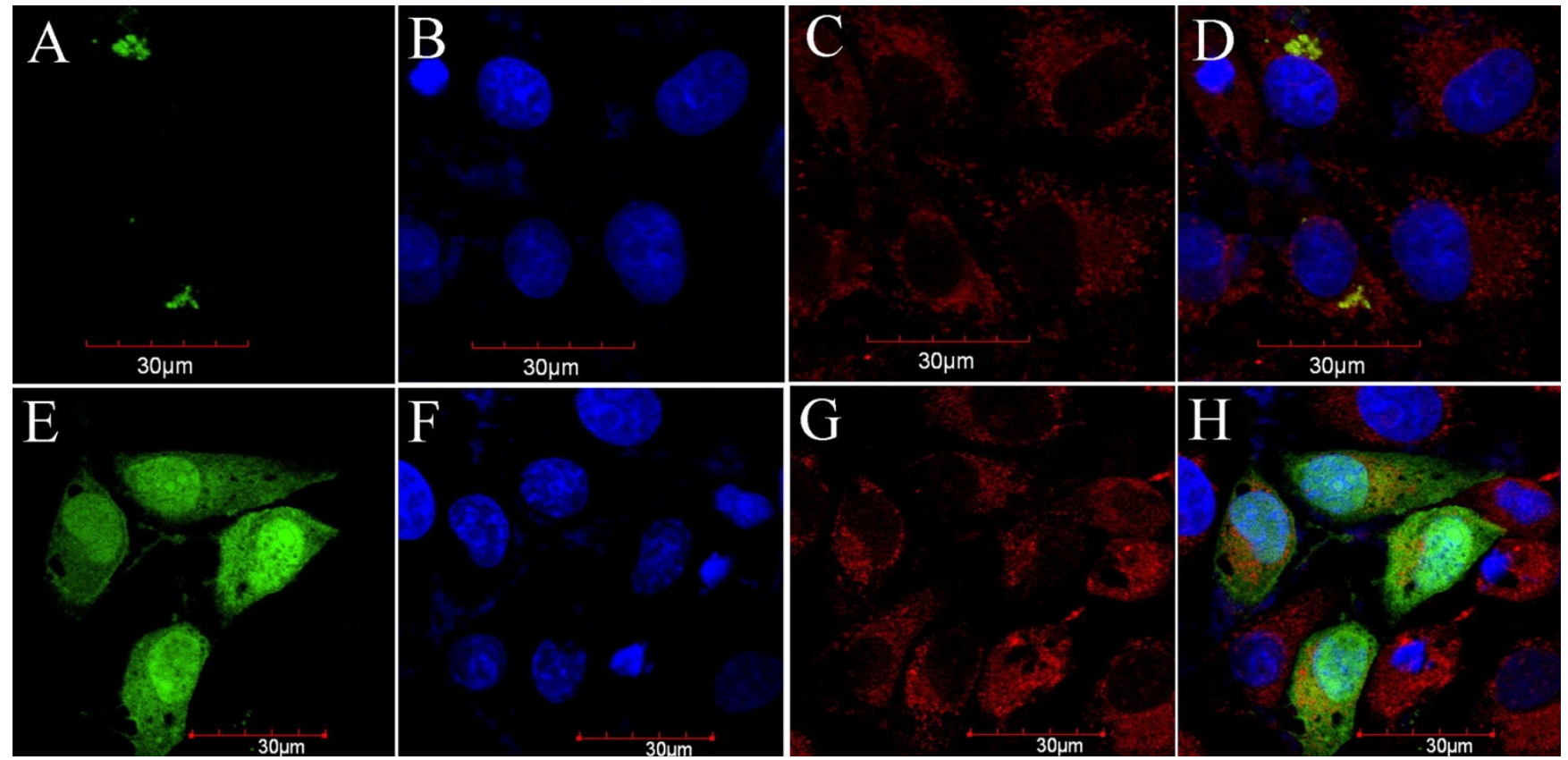

Figure 5

Subcellular distribution of CGI- 46 protein tagged with GFP. The CGI-I46-GFP fusion protein localized in Golgi complex marked with fluorescein isothiocyanate $(A)$. Red fluorescence of mitochondria were stained with the mitochondrial-specific dye, Mito-Tracker Red (B) and blue fluorescence of nuclei were stained with Hoechst33342 (C). The overlay images were produced by merging all three signals together (D). The control micrographs $(\mathrm{E}-\mathrm{H})$ showed the GFP in the cytoplasm. Bars represent $30 \mu \mathrm{M}$.

\section{Functional analysis in muscle tissue related to meat production}

PNAS-4 mRNA showed a widespread expression with the highest levels in muscle tissue, and could be detected at all times during the skeletal muscle development. In more detail, the expression of PNAS-4 tends to decrease gradually from prenatal day 33 to day 90, an important period for development of muscle fibers and determination of muscle fiber numbers $[1,16,17]$. The muscle fiber number appears to increase as a result of the decrease of PNAS-4 mRNA expression level during prenatal muscle development, which was consistent with that the PNAS-4 is involved in apoptosis[8]. However, the expression profiles of Tongcheng pigs and Landrace pigs were not complete similar in early embryonic development, and this kind of difference may be related to breed difference [5]. The PNAS-4 mRNA expression decreased faster in early Landrace pig development, and this result may be correlated with the high number of primary fibers found in Landrace compared with Tongcheng pigs and other indigenous Chinese breeds [18-21]. In other words, there might be a positive correlation between the decrease speed of PNAS-4 mRNA expression level in embryonic stage and porcine muscle fiber number. Muscle fiber number is an important determinant of postnatal growth such that pigs with a high fiber number tend to grow faster than pigs with a lower fiber number [22]. This is also supported by the carcass weight of Landrace compared to Tongcheng pigs[18]. After birth, the expression of PNAS-4 mRNA in muscle tissue was increased, which could be

Table 2: Association analyses between SNP A I8I3C and three fat-related traits

\begin{tabular}{|c|c|c|c|c|c|c|}
\hline \multirow[b]{2}{*}{ Traits } & \multicolumn{3}{|c|}{ SNP AI8I3C Genotype (mean \pm SE) } & \multicolumn{3}{|l|}{ P-value } \\
\hline & $\mathrm{AA}(67)$ & $A C(52)$ & $\mathrm{CC}(37)$ & AA-AC & $\mathrm{AA}-\mathrm{CC}$ & $\mathrm{AC}-\mathrm{CC}$ \\
\hline Percentage of leaf fat & $2.794 \pm 1.31$ & $3.259 \pm 1.2$ & $5.261 \pm 1.44$ & 0.847 & $0.008 * *$ & $0.017^{*}$ \\
\hline Percentage of leaf and caul fat & $5.010 \pm 2.29$ & $5.928 \pm 2.6$ & $9.933 \pm 2.96$ & 0.806 & $0.012^{*}$ & $0.028^{*}$ \\
\hline BFT between $6^{\text {th }}$ and $7^{\text {th }}$ ribs & $3.257 \pm 0.93$ & $3.199 \pm 0.71$ & $4.262 \pm 0.93$ & 0.183 & 0.324 & $0.039 *$ \\
\hline
\end{tabular}

* represents $P<0.05$, ** represents $P<0.01$ 
attributed to an increase in length and girth of the muscle fibres and/or muscle function [1]. Consistent with this, the highest expression of the gene was recorded in skeletal muscle of mature pigs. The protein was found to localize in the Golgi complex. It was thus deduced that PNAS-4 protein acted more possibly as a regulator than as a structural protein, which was generally in agreement with the opinion that PNAS-4 may be a pro-apoptotic gene [8].

\section{PNAS-4 as a candidate gene or QTL for fat deposition}

Porcine PNAS-4 gene mapped to q11-16 of SSC10, closely linked to marker SW497. It showed that several quantitative trait loci (QTL) related to growth and carcass traits, such as average daily gain (ADG), Backfat Thickness (BFT), Carcass Weight (CCWT), Ham Weight (HAMWT), are located on this chromosome region in the Pig QTL Database release [23-25]. Consistent with this, significant associations between A1813C SNP genotypes of PNAS-4 and three fat-related traits were found in our experimental pig populations. Moreover, the three fat traits values of pigs with homozygous $\mathrm{CC}$ were higher than that of the pigs with other genotypes $(P<0.05)$. Our findings have also revealed that allele C of SNP A1813C was prevalent in four Chinese indigenous breeds whereas allele A had higher frequency in Landrace and Large White. Interestingly, western commercial pig breeds (Duroc, Large White and Landrace) are well known for their high growth rate and lean meat percentage [26]. These correlated results suggest that the pigs with allele C in SNP A1813C will have higher fat content. In order to confirm it, further investigations in the use of the gene for commercial breeding are recommended.

\section{Conclusion}

We cloned and characterized the full-length cDNA of porcine PNAS-4 gene. Expression profiles and gene structure suggest that this gene was regulated negatively at the posttranscriptional level, both temporal and spatial. It might play a negative role in modulating muscle fiber numbers, and act as an important factor affecting the muscle mass efficiency. Unexpectedly, association analysis revealed that allele C of SNP A1813C was prevalent in four Chinese indigenous breeds whereas allele A had higher frequency in Landrace and Large White, and the pigs with allele $\mathrm{C}$ in SNP A1813C will have higher fat content. It is a potential genetic marker for animal breeding.

\section{Methods \\ cDNA isolation and sequence analysis}

BLAST in the pig expressed sequence tags (ESTs) database using the human PNAS-4 mRNA sequence [GenBank: $\underline{N M}$ 016076] as probe, revealed three porcine ESTs [GenBank: CN156918, CV877591 and AJ665351]. To obtain the fulllength cDNA, primer set GAPF/GAPR (Table 3) was used to amplify the unknown nucleotide sequence between ESTs CV877591 and AJ665351, and the primer 5GSP (Table 3 ) in combination with the Universal Primer A Mix (UPM) supplied in the SMART ${ }^{\mathrm{TM}}$ RACE Kit (Clontech Inc, Palo Alto, CA, USA) used to amplify the 5'-end of the gene. Rapid amplification of cDNA ends (RACE) PCR was carried out in a PTC-200 thermal cycler (Bio-Rad, Richmond, CA, USA) with touchdown PCR conditions: 3 min at $95^{\circ} \mathrm{C} ; 5$ cycles of $94^{\circ} \mathrm{C}$ for $20 \mathrm{~s}, 72^{\circ} \mathrm{C}$ for $3 \mathrm{~min} ; 5$ cycles of $94^{\circ} \mathrm{C}$ for $20 \mathrm{~s}, 70^{\circ} \mathrm{C}$ for $30 \mathrm{~s} ; 72^{\circ} \mathrm{C}$ for $3 \mathrm{~min} ; 32$ cycles of $94^{\circ} \mathrm{C}$ for $20 \mathrm{~s}, 68^{\circ} \mathrm{C}$ for $30 \mathrm{~s} ; 72^{\circ} \mathrm{C}$ for $3 \mathrm{~min} ; 5 \mathrm{~min}$ at $72^{\circ} \mathrm{C}$. The PCR products were purified by agarose gel electrophoresis and sequenced. Functional elements analysis of the putative protein and UTR were performed using the

Table 3: Primers and probe employed in these experiments

\begin{tabular}{|c|c|c|c|}
\hline Function & Primer name & Primer and probe sequences $\left(5^{\prime}-3^{\prime}\right)$ & $\mathrm{Tm}$ \\
\hline \multirow[t]{3}{*}{ Cloning } & GAPF & CTCCAAAGTCACACGCTCAGAAC & 62 \\
\hline & GAPR & ATAGTCCTACCCCACGAAGAAGC & \\
\hline & $5 G S P$ & GGAAGGGTATGCAGGAGCTGAAGTAGGC & 71 \\
\hline Subcellular & P4GFPF & CGGCTCGAGGGATGGGGGCTAACC & 63 \\
\hline localization & P4GFPR & GAGAAGCTTAGAGTTTGGTGTGGCG & \\
\hline Real-time & Real-time F & CCCAGGAAATGCTTCTGAACTAG & 60 \\
\hline \multirow[t]{5}{*}{ PCR } & Real-time R & CCCACAAAGAATCTCTGATAAAGC & \\
\hline & ProbeP4 & AAGCTGTTGTTTTGGGGAGCACTG & \\
\hline & ACTB F & GGATGCAGAAGGAGATCACG & 60 \\
\hline & ACTB R & CTCGTCGTACTCCTGCTTGC & \\
\hline & ProbeBeta & ATCAAGATCATCGCGCCTCCCGAGC & \\
\hline \multirow[t]{2}{*}{ Mapping } & MapF & TGGCAGAGCGGTCGTCACTTAGGC & 65 \\
\hline & MapR & GAGCAGAATCTCCTCCCACGCACCAT & \\
\hline \multirow[t]{4}{*}{ SNPs detection } & SNPFI & CTAGAACCACTCAAACCAAGCAGC & 62 \\
\hline & SNPRI & ATCAGGCAGGTAAAAGGATAACGG & \\
\hline & SNPF2 & GCCTTCTGAGTAGCAGTATGAGTTG & 62 \\
\hline & SNPR2 & CCTGCGAGAACTGAGAATAATCC & \\
\hline
\end{tabular}


PROSITE program[27], SignalP 3.0 server[28] and UTRScan[29], respectively.

\section{QPCR analysis of gene expression patterns}

Fifteen tissues (stomach, large intestine, kidney, lymph node of neck, small intestine, liver, heart, longissimus dorsi muscle, lung, gastrocnemius, biceps femoris muscle, brain, backfat, semitendinosus and spleen) were obtained from three Chinese indigenous Wuzhishan (a Chinese mini pig breed) sows. Three pig embryos were collected from every pregnant female during three embryonic periods $(33,65$, and $90 \mathrm{dpc})$ and three postnatal periods $(2$, 28 days and adult (160 days)). The longissimus dorsi muscle were harvested, mixed, frozen in liquid nitrogen, and stored at $-80^{\circ} \mathrm{C}$. Furthermore, three Landrace pigs were employed to determine expression differences between western and Chinese pig breeds in prenatal stages. All animal procedures were performed according to guidelines developed by the China Council on Animal Care and protocol approved by Animal Care and Use Committee of Hubei Province, PR China.

QPCR was performed with the Chromo4 ${ }^{\mathrm{TM}}$ Real-Time PCR Detector (Bio-Rad) using gene-specific primers and Taqman probes (Table 3 ). Total RNA ( $4 \mu \mathrm{g})$, extracted from tissues using the Trizol reagent (Invitrogen, Carlsbad, CA, USA) and treated with RNase-free DNase (MBI Fermentas, St. Leon-Rot, Germany). RNA quality was assessed with agarose gel electrophoresis and the ND-1000 Spectrophotometer (NanoDrop Technologies, USA), and was discarded if the 260/280 ratio was not between 1.8 and 2.1. It was reverse-transcribed into cDNA using M-MLV reverse transcriptase (Promega Corp., Madison, WI, USA). cDNA synthesis was performed in duplicate. Both beta-actin gene $(A C T B)$ and glyceraldehyde-3-phosphate dehydrogenase $(G A P D H)$ were consistently expressed in all tissues of this assay, so we selected the ACTB, one of the two housekeeping genes, as an internal control for normalization purposes. The minus RT control with primers for ACTB was performed to test if products were derived from DNA. Relative transcript quantification was performed using standard curves generated for ACTB and PNAS-4 gene from a 10-fold serial dilution of cDNA. Pooled cDNA from a subset of the gastrocnemius samples examined in this study was used to generate the standard curves. In this assay, the efficiency of ACTB and PNAS-4 gene primers were $96.5 \%$ and $96.95 \%$, respectively. The cycling conditions consisted of an initial, single cycle of $95^{\circ} \mathrm{C}$ for 3 min, followed by 35 cycles of $15 \mathrm{~s}$ at $94^{\circ} \mathrm{C}$ and $1 \mathrm{~min}$ at $60^{\circ} \mathrm{C}$. Each reaction (in $20 \mu \mathrm{l}$ ) contained $1 \times$ PCR buffer (TaKaRa, Dalian, P. R. C.), $0.4 \mu \mathrm{M}$ gene-specific primers and $0.2 \mu \mathrm{M}$ probe, $50 \mu \mathrm{M}$ of each dNTP, $3 \mathrm{mM} \mathrm{MgCl}_{2}, 2.0$ U Taq DNA polymerase (TaKaRa) plus $2 \mu \mathrm{l}$ normalized template cDNA. All PCR amplifications were performed in triplicate for each RNA sample and gene expression lev- els were quantified relative to $A C T B$ expression using Gene Expression Macro software (Bio-Rad). The results were analyzed using the $2^{-\Delta \Delta \mathrm{Ct}}$ method described previously[30]. Differences in gene expression between groups were evaluated using Student's t-test and were considered statistically significant at $P<0.05$.

\section{Intracellular distribution of the porcine PNAS-4 gene}

The intracellular distribution of porcine PNAS-4 protein was studied by fluorescence and confocal analysis of pig kidney epithelial cells (PK15) cells transiently transfected with P4-pEGFP-C1 construct. The ORF, encoding porcine PNAS-4 protein, was amplified by PCR using the primers (P4GFPF/P4GFPR, Table 3) designed from its cDNA sequence and subcloned into the Xho I-Hind III site of the pEGFP-C1 vector (BD Biosciences Clontech, CA, USA).

PK15 cells were cultured in Dulbecco's modified Eagle's medium (DMEM) supplemented with 10\% fetal calf serum (GIBCO-BRL, Grand Island, NY), 4 mM glutamine, $100 \mathrm{U} / \mathrm{ml}$ penicillin, and $0.1 \mathrm{mg} / \mathrm{ml}$ streptomycin under humidified air containing $5 \% \mathrm{CO}_{2}$ at $37^{\circ} \mathrm{C}$ and seeded onto cover slips in 6-well plates. The PK15 cells were plated at $5 \times 10^{5} / \mathrm{ml}$ and transfected with P4-pEGFP-C1/ N3 constructs ( $1 \mu \mathrm{g}$ of plasmid DNA) using Lipofectamine $^{\mathrm{TM}} 2000$ reagent according to the manufacturer's instructions until they were grown to $80-90 \%$ confluence.

Twenty-four hours after transfection, the cells were incubated at $37^{\circ} \mathrm{C}$ for $30 \mathrm{~min}$ in growth medium containing $200 \mathrm{nM}$ MitoTracker Red $\mathrm{CM}-\mathrm{H}_{2}$ Xros (Molecular Probes, Eugene, Oregon, USA) for mitochondrial labeling. Then the cells were fixed with pre-warmed growth medium containing $3.7 \%$ formaldehyde for $15 \mathrm{~min}$ at $37^{\circ} \mathrm{C}$. After the final washing steps and incubation with $10 \mu \mathrm{M}$ Hoechst33342 for $10 \mathrm{~min}$, the slides were mounted, sealed and analyzed by Olympus FluoView ${ }^{\mathrm{TM}}$ FV1000 Confocal Microscope. The software FV1000 Viewer was used to generate individual fluorescent pictures as well as overlay pictures that demonstrated the relative distribution of the fusion protein.

\section{Chromosome mapping by SCH and IMpRH}

The French SCH panel composed of 27 pig/rodent hybrids [31] was used for the regional assignment of PNAS-4 gene on the SSC. To more precisely map genes, the IMpRH panel consisting of 118 hybrid clones obtained by fusing irradiated pig cells with the recipient hamster cell was employed [32]. The PCR was performed in a total volume of $10 \mu \mathrm{L} 1 \times$ PCR buffer (TaKaRa), containing $25 \mathrm{ng}$ panel DNA, $0.3 \mu \mathrm{M}$ each primer (MapF, MapR, Table 3), $75 \mu \mathrm{M}$ each dNTP, $1.5 \mathrm{mM} \mathrm{MgCl}_{2}$, and 1.0 U Taq DNA polymerase (TaKaRa). The PCR cycling conditions were: Initial denaturation at $95^{\circ} \mathrm{C}$ for $3 \mathrm{~min}$, followed by 32 cycles $\left(20 \mathrm{~s}\right.$ at $94^{\circ} \mathrm{C}, 30 \mathrm{~s}$ at $65^{\circ} \mathrm{C}$ and 30 
s at $72^{\circ} \mathrm{C}$ ). Statistical analysis of SCH PCR results were performed using the program [33] available for regional assignment of genetic markers. The results of radiation hybrid PCR products were analysed with the IMpRH mapping tool [34].

\section{Polymorphism detection and association with meat traits} Four Chinese indigenous pig breeds (Xiang $(\mathrm{N}=42)$, Bamaxiang( $\mathrm{N}=45)$, Wuzhishan $(\mathrm{N}=43)$ and Tongcheng $(\mathrm{N}=44)$ pigs) and two western white breeds (Large White $(\mathrm{N}=215)$ and Landrace $(\mathrm{N}=15))$ were used to analyze genetic variability. Association analyses were performed in our experimental populations that contained three pure breeds, Tongcheng $(\mathrm{N}=44)$, Landrace $(\mathrm{N}=15)$ and Large White ${ }^{\mathrm{a}}(\mathrm{N}=19)$, and a pair of three-breed cross, Landrace $\times$ (Large White $\times$ Tongcheng) $(\mathrm{N}=44)$ and Large White $\times$ (Landrace $\times$ Tongcheng) $(\mathrm{N}=35)$. Growth traits (average daily gain), carcass and meat quality traits (live weight at slaughter, carcass length, dressing percent, loin muscle area, meat color, marbling, drip loss, 0 h loin muscle $\mathrm{PH}$ and shear force) were studied. Fat traits studied were percentage of leaf fat, percentage of leaf and caul fat, and backfat thickness between 6 th and 7 th ribs.

Two pairs of primers (SNPF1/SNPR1 located in intron 2 and SNPF2/SNPR2 located in 3'UTR) were designed using the submitted sequences [GenBank: DQ406743 and DQ435075]. The PCR products were cloned into the Teasy vector and sequenced to identify the polymorphisms in the porcine PNAS-4 gene.

Associations between growth traits, carcass traits and meat quality traits on the one hand and genotype on the other hand were studied using a two-step analysis method. Briefly, in the first step, a preliminary general linear model without the genotype information was used to eliminate system effects, including sex, combination and batch, using the SPSS program with the following model:

$$
Y_{i j k l}=\mu+C_{i}+B_{j}+S_{k}+(C B)_{i j}+(B S)_{j k}+e_{i j k l}
$$

where $Y_{i j k l}$ is phenotypic value of the target trait, $\mu$ is the population mean, $C_{i}$ is the combination (including breed) effect, $B_{j}$ is the batch effect, $S_{k}$ is the sex effect and $e_{i j k l}$ is random error effect for each observation. In addition, the interaction effects between combination and batch $(C B)_{i j}$, and between batch and sex $(B S)_{j k}$, were also considered. In the second step, the resulting standardized residual values were used to partition the effects of the genotypes using the one-way analysis of variance (ANOVA) model. Simultaneously, significant difference tests between different genotypes were performed with Bonferroni $t$ tests [35].

\section{Abbreviations}

dpc: days post conception, ESTs: expressed sequence tags, GFP: green fluorescent protein, HSC: homo sapiens chromosome, IMpRH: INRA University of Minnesota porcine radiation hybrid, ORF: open reading frame, PK15: Pig Kidney Epithelial cells, QTL: quantitative trait loci, RACE: rapid amplification of cDNA ends, $\mathrm{SCH}$ : somatic cell hybrid, SNPs: single nucleotide polymorphisms, SSC: sus scrofa chromosome, UTR: untranslated region.

\section{Authors' contributions}

DM performed research and drafted the manuscript. ZM participated in the design and the realization of the experiment. MFWtP provided DNA samples for SNP genotyping, and finalized the writing. XL participated in cell culture and subcellular localization. SY was responsible for the data management. HW contributed to bioinformatics analysis. HLW participated in SNP identification. KL conceived and coordinated the study and corrected the manuscript.

\section{Acknowledgements}

We are grateful to Dr. Martine Yerle for providing the RH panel. This research was supported by National Natural Science Foundation of China (304003 I I), Guangdong Natural Science Foundation (07300492), National 973 Project (2006CB I02 I05) and National 863 Project (2006AA I0ZI 35), the State Platform of Technology infrastructure (2005DKA2 I I0I), the Project of Science and Technology Innovation Team "Research and Improvement of Domestic Animal Germplasm", Institute of Animal Science, Chinese Academy of Agricultural Science (ywf-td-I).

\section{References}

I. Rehfeldt C, Stickland NC, Fiedler I, Wegner J: Environmental and Genetic Factors as Sources of Variation in Skeletal Muscle Fibre Number. Basic Appl Myol 1999, 9(5):235-253.

2. Zhao SH, Nettleton D, Liu W, Fitzsimmons C, Ernst CW, Raney NE, Tuggle CK: Complementary DNA macroarray analyses of differential gene expression in porcine fetal and postnatal muscle. J Anim Sci 2003, 8 I (9):2179-2 I88.

3. Te Pas MFW, de Wit A, Priem J, Cagnazzo M, Davoli R, Russo V, Pool $\mathrm{MH}$ : Transcriptome expression profiles in prenatal pigs in relation to myogenesis. J Muscle Res Cell Motil 2005, 26: I 57-I65.

4. Te Pas MFW, Pool MH, Hulsegge I, Janss LLG: Analysis of the differential transcriptome expression profiles during prenatal muscle tissue development. Arch Tierz Dummerstorf 2006, 49: $110-115$

5. Cagnazzo M, te Pas MFW, Priem J, de Wit A, Pool MH, Davoli R, Russo V: Comparison of prenatal muscle tissue expression profiles of two pig breeds differing in muscle characteristics. J Anim Sci 2006, 84: I- I0.

6. Lehnert SA, Reverter A, Byrne KA, Wang Y, Nattrass GS, Hudson NJ Greenwood PL: Gene expression studies of developing bovine longissimus muscle from two different beef cattle breeds. BMC Developmental Biology 2007, 7(95): I- I3.

7. Zhu ZM: Identification of pork production trait candidate genes by cDNA macroarray. In Department of Animal Science Wuhan, Huazhong Agricultural University; 2004.

8. Filippov V, Filippova M, Sinha D, Duerksen-Hughes PJ: PNAS-4: A Novel Pro-Apoptotic Gene Activated During the Early Response to DNA Damage [abstract]. 2005.

9. Daniel SB: Modelling the p53 gene regulatory network. In Centre for Mathematics and Physics in the Life Sciences and Experimental Biology London , University of London; 2006.

10. Yan F, Qian M, Yang F, Cai F, Yuan Z, Lai S, Zhao X, Gou L, Hu Z, Deng $\mathrm{H}$ : A novel pro-apoptosis protein PNAS-4 from $X$ eno- 
pus laevis: cloning, expression, purification, and polyclonal antibody production. Biochemistry (Moscow) 2007, 72(6):664-67I.

II. Meyers SN, Rogatcheva MB, Larkin DM, Yerle M, Milan D, Hawken RJ, Schook LB, Beever JE: Piggy-BACing the human genome II. A high-resolution, physically anchored, comparative map of the porcine autosomes. Genomics 2005, 86(6):739-752.

12. Te Pas MFW, Cagnazzo M, de Wit AAC, Priem J, Pool M, Davoli R: Muscle transcriptomes of Duroc and Pietrain pig breeds during prenatal formation of skeletal muscle tissue using microarray technology. Arch Anim Breed 2005, 48: |41-147.

13. Lai EC, Burks C, Posakony JW: The K box, a conserved 3' UTR sequence motif, negatively regulates accumulation of enhancer of split complex transcripts. Development 1998, I 25(20):4077-4088.

14. Lai EC: Micro RNAs are complementary to 3' UTR sequence motifs that mediate negative post-transcriptional regulation. Nat Genet 2002, 30(4):363-364.

15. Lai EC, Posakony JW: The Bearded box, a novel 3' UTR sequence motif, mediates negative post-transcriptional regulation of Bearded and Enhancer of split Complex gene expression. Development 1997, I 24:4847-4856.

16. Swatland $\mathrm{HJ}$ : Muscle growth in the fetal and neonatal pig. J Anim Sci 1973, 37(2):536-545.

17. Swatland HJ: Structure and Development of Meat Animals and Poultry. Technomic Publishing Co Inc Lancaster, PA 1994.

18. Tang Z, Li Y, Wan P, Li X, Zhao S, Liu B, Fan B, Zhu M, Yu M, Li K: LongSAGE analysis of skeletal muscle at three prenatal stages in Tongcheng and Landrace pigs. Genome Biol 2007, 8(6): $R|| 5$.

19. Ford SP, Youngs CR: Early embryonic development in prolific Meishan pigs. / Reprod Fertil Suppl 1993, 48:27I-278.

20. White BR, Lan YH, McKeith FK, Novakofski J, Wheeler MB, McLaren DG: Growth and body composition of Meishan and Yorkshire Barrows and Gilts. J Anim Sci 1995, 73:738-749.

21. Rivera RM, Youngs CR, Ford SP: A comparison of the number of inner cell mass and trophectoderm cells of preimplantation Meishan and Yorkshire pig embryos at similar developmental stages. Reprod Fertil 1996, 106: I I I-I I6.

22. Dwyer CM, Fletcher JM, Stickland NC: Muscle cellularity and postnatal growth in the pig. J Anim Sci 1993:3339-3343.

23. Dragos-Wendrich M, Moser G, Bartenschlager H, Reiner G, Geldermann $\mathrm{H}$ : Linkage and QTL mapping for Sus scrofa chromosome 10. J Anim Breed Genet 2003, I 20(I):82-88.

24. Quintanilla R, Milan D, Bidanel JP: A further look at quantitative trait loci affecting growth and fatness in across between Meishan and Large White pig populations. Genet Sel Evol 2002, 34(2): 193-210.

25. Kim CW, Hong YH, Yun S, Lee SR, Kim YH, Kim MS, Chung KH, Jung WY, Kw EJ: Use of Microsatellite Markers to Detect Quantitative Traiy Loci in Yorkshire Pigs. J Reprod Dev 2006, 52(2):229-237.

26. Young LD: Effects of Duroc, Meishan, Fengjing, and Minzhu boars on carcass traits of first-cross barrows. J Anim Sci 1992, 70:2030-2037.

27. The PROSITE database [http://ch.expasy.org/prosite/]

28. SignalP 3.0 server [http://www.cbs.dtu.dk/services/SignalP/]

29. UTRscan [http://www.ba.itb.cnr.it/BIG/UTRScan/]

30. Livak KJ, Schmittgen TD: Analysis of relative gene expression data using real-time quantitative PCR and the 2(-Delta Delta C(T)) Method. Methods (San Diego, Calif 200I, 25(4):402-408.

31. Yerle M, Echard G, Robic A, Mairal A, Dubut-Fontana C, Riquet J, Pinton P, Milan D, Lahbib-Mansais Y, Gellin J: A somatic cell hybrid panel for pig regional gene mapping characterized by molecular cytogenetics. Cytogenet Cell Genet 1996, 73(3): 194-202.

32. Yerle M, Pinton P, Robic A, Alfonso A, Palvadeau Y, Delcros C, Hawken R, Alexander L, Beattie C, Schook L, Milan D, Gellin J: Construction of a whole-genome radiation hybrid panel for highresolution gene mapping in pigs. Cytogenet Cell Genet 1998, 82(3-4): $182-188$.

33. Chevalet C, Gouzy J, SanCristobal-Gaudy M: Regional assignment of genetic markers using a somatic cell hybrid panel: a WWW interactive program available for the pig genome. Comput Appl Biosci 1997, I3(I):69-73.

34. Milan D, Hawken R, Cabau C, Leroux S, Genet C, Lahbib Y, Tosser G, Robic A, Hatey F, Alexander L, Beattie C, Schook L, Yerle M, Gellin
J: IMpRH server: an RH mapping server available on the Web. Bioinformatics 2000, 16(6):558-559.

35. Johnson DE: Applied multivariate methods for data analysts. Stamford: Thomson Learning 1998:286-316.
Publish with Biomed Central and every scientist can read your work free of charge

"BioMed Central will be the most significant development for disseminating the results of biomedical research in our lifetime. "

Sir Paul Nurse, Cancer Research UK

Your research papers will be:

- available free of charge to the entire biomedical community

- peer reviewed and published immediately upon acceptance

- cited in PubMed and archived on PubMed Central

- yours - you keep the copyright 